\title{
Predictors of Chronic Physical and Mental Quality of Life Following Traumatic Brain Injury
}

\author{
Shahrokh Yousefzade-Chabok ${ }^{1}$, Sara Ramezani Kapourchali1,2* ${ }^{*}$ Zoheir Reihanian ${ }^{3}$, \\ Ehsan Kazemnezhad Leili' ${ }^{1}$ Anoush Dehnadi Moghadam ${ }^{1}$, Zahra Mohtasham Amiri1 \\ ${ }^{1}$ Guilan University of Medical Sciences, Guilan Road Trauma Research Center, Rasht, Iran \\ ${ }^{2}$ Tehran University of Medical Sciences, Neuroscience Department, Tehran, Iran \\ ${ }^{3}$ Guilan University of Medical Sciences, Neurosurgery Department, Rasht, Iran \\ Email: s.ramezanislp@gmail.com
}

Received 12 December 2013; revised 19 January 2014; accepted 27 January 2014

Copyright (C) 2014 by authors and Scientific Research Publishing Inc.

This work is licensed under the Creative Commons Attribution International License (CC BY). http://creativecommons.org/licenses/by/4.0/

(c) (i) Open Access

\begin{abstract}
Objective and Background: This study aimed at determining the predictors of chronic physical and mental quality of life (QOL) in patients with traumatic brain injury (TBI) focusing on neuropsychological functions post trauma. Materials and Methods: This is a longitudinal study in which 257 patients having inclusion criteria were enrolled. Neuropsychological tasks including logical memory, verbal paired associates, visual memory, verbal expression, auditory comprehension, semantic judgment and semantic categories were implemented. The appearance of psychiatric disorder, Agnosia, Apraxia, Dysarthria and pragmatic linguistic disorder post trauma were evaluated at discharge. QOL was studied 6 months after injury by filling SF-36 questionnaire via phone interview with patients. Results: Appearance of some post-traumatic disorders including agnosia, pragmatic linguistic disorder and psychiatric disorder were significantly correlated to poor QOL. The final step of logistic regression model showed that TBI severity, verbal memory, auditory comprehension and semantic acceptability scores were predictors of unfavorable mental QOL as well as TBI severity, injury severity scale (ISS) score and multifocal lesions for unfavorable physical QOL. Discussion: Thus, it is recommended that clinicians choose medical therapeutic priorities to improve the verbal neuropsychological sequela and provide preliminaries for a chronic favorable mental QOL. Furthermore, to prevent of chronic unfavorable physical QOL, early care of organic injuries should be considered especially in patients with severe and multifocal TBI.
\end{abstract}

\section{Keywords}

Traumatic Brain Injury; Physical and Mental Quality of Life; Short Form-36 Questionnaire;

\footnotetext{
${ }^{*}$ Corresponding author.
}

How to cite this paper: Yousefzade-Chabok, S., Kapourchali, S.R., Reihanian, Z., Leili, E.K., Moghadam, A.D. and Amiri, Z.M. (2014) Predictors of Chronic Physical and Mental Quality of Life Following Traumatic Brain Injury. Health, 6, 496-503. 


\section{Neuropsychological Functions}

\section{Introduction}

Traumatic brain injury is one of the major causes of persistent disability in people under 45 years old [1]. These disabilities underlie many of daily dysfunctions in individuals, playing an important role in reducing the functional independence, social and communicative activities of patients which consequently bring about a poor QOL, inhibiting motility and make them isolated [2] [3]. Dynamic mental processes which are impaired in these patients include attention, working memory, organizing sensory information, linguistic perception and expression, reasoning and problem-solving which are among main neuropsychological functions. Impairment in perception and expression of emotional load of speech through either verbal prosody or facial gestures is a pragmatic linguistic disorder after TBI and involves brain areas related to emotions such as amygdala and other parts related to limbic system which are also parts of the brain most susceptible to damage from trauma [4]. Damage to orbitofrontal cortex, a part of anterior limbic cortex, leads to anti-social behaviors and mood disorders [5] [6]. Studies related to assessment of post-traumatic long-term outcomes suggest that persistent cognitive and emotional disorders are adverse outcomes after TBI which affect satisfaction and quality of life [7] [8]. De Almeida Lima and his coauthors found that in patients with mild brain injury, 18 months after trauma QOL in all dimensions of SF-36 except physical function decreased significantly and neuroimaging findings in acute phase could predict mental health dimension of QOL in SF-36 scale in chronic phase [9]. In another study, it was discovered that poor social and psychological dimensions of QOL one year after injury were significantly correlated with age, gender, post-trauma cognitive deficit but not with severity of brain injury [10]. In an effort which was carried out to determine the predictors of QOL 9 months after subarachnoid hemorrhage, patients with Glasgow Outcome Scale (GOS) 5 at discharge had a poor QOL in SF-36 general health and social dimensions which was predictable by factors such as severity of initial hemorrhage and acute hydrocephalus [11]. Quality of life is known as a valid and proper measuring criterion of clinical outcome [12]. Despite of these evidences, one ambiguity is unanswered yet: which of the acute neuropsychological functions are most crucial for prediction of chronic mental QOL? This study aimed at determining the acute effectors on chronic physical and mental QOL in TBI patients. If we obtain this purpose, an opportunity will be provided for prioritization of early intervention in order to reduce the effect of deteriorating factors on chronic QOL, eventually causing a good chronic QOL for suffered patients.

\section{Material \& Method}

In a longitudinal cross-sectional study, 257 Persian speaking patients with brain injury documented by abnormal CT finding in age range of 18 to 65 years who were treated in neurosurgery ward of Poursina Teaching Hospital, North of Iran from June 2010 to December 2011 were consecutively entered in the study after obtaining written informed consent. The participants had good recovery or mild disability according to GOS [13] at discharge. Patients with following conditions were excluded: mental retarded, non-traumatic physical-motor problem, history of speech and linguistic disorders, history of psychological problems and antipsychotic and antidepressant drugs consumption, history of neurological problems such as neurodegenerative diseases, stroke, seizure and brain tumor, spinal cord injury and previous brain damage, history of drug abuse, and patients developing Anosognosia after TBI. There was a 12\% dropout of initial sampling, 31 patients discontinued this research. The algorithm of study from screening of subjects and initial sampling to final step is illustrated in Figure 1. Overall, remained samples were separated into two groups with respect to QOL state. 118 and 108 subjects were belonged to favorable and unfavorable QOL, respectively. These groups were matched in terms of the gender and education level regarding the Table 1 . The severity of TBI was determined according to primary post resuscitation consciousness based on GCS [13] and injury severity based on ISS [14] were identified by a physician. CT scan was performed within $24 \mathrm{hrs}$ after trauma and type and site of lesion were diagnosed by an independent radiologist. We regarded two injury classifications based on type and site of injury. First classification was performed according to its morphology [13]. Wherever a kind of bleeding was accompanied by one or more other lesions such as edema, contusion, pneumocephalus or another hemorrhage, we added a subcategory as "accompanied 


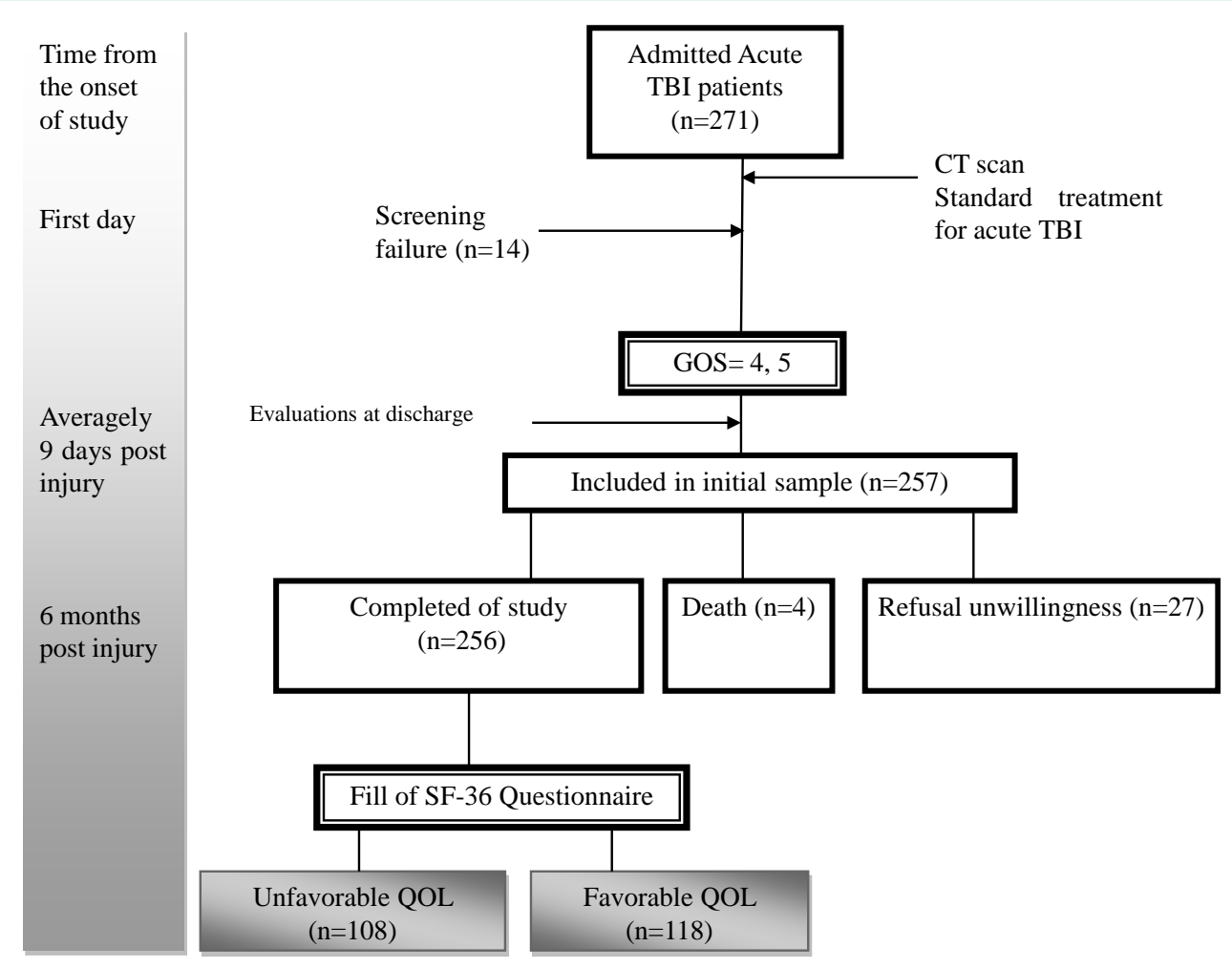

Figure 1. Algorithm of study accompanied by time course.

hemorrhage”. Last classification concerned anatomical location including involved brain areas such as cerebral lobes and brain stem. Multiple lesions were defined as homogenesis or heterogenesis, homolateral or bilateral lesions in at least two different portions. Neuropsychological assessments were carried out at discharge using subtests from Persian Aphasia Test including confronting naming and auditory comprehension such as word discrimination and simple commands [15] as well as semantic acceptability and categories subtests extracted from Bilingual Aphasia Test [16]. Revised Persian version of Wechsler Adult Memory Scale was also used to evaluate logical memory and verbal paired associates and visual memory after brain trauma [17]. Then, by using direct observation method and providing a set of tasks and predefined commands for patients in a semi-structured evaluation, Agnosia, dysarthria, pragmatic linguistic disorder and Apraxia were assessed by a speech and language pathologist. Psychiatric disorder post trauma was evaluated by a psychiatrist according to DSMIV-TR criteria [18]. To assess QOL 6 months after injury, the patients were interviewed via telephone call. The Persian SF-36 questionnaire for assessment of QOL was filled. SF-36 scoring is between 0 - 100, higher scores indicate a good QOL. Scores $>60$ signify good QOL and scores $<60$ suggest unfavorable QOL [19].

\section{Data Analysis}

Collected data was analyzed by SPSS Version 16.00. Univariate analyses were performed using Chi-square test to study the difference of qualitative variables between QOL groups. In order to determine the acute predictive factors for chronic physical and mental QOL, multiple logistic regression by Back Ward method was applied. Parametric T-test was administered to examine the significant difference of quantitative variables between favorable and unfavorable QOL groups. Hypothesis tests were two-tailed and the significance level in all tests was considered 0.05 .

\section{Results}

Studying the results of univariate analysis to determine the effective factors on chronic QOL of patients showed that neurosurgical intervention was not a significant effective factor. Younger patients $(\mathrm{P}<0.029)$ had poorer QOL than older ones. High ISS score (mean \pm SD: $27.28 \pm 13.95, \mathrm{t}=7.74, \mathrm{df}=224, \mathrm{P}>0.001$ ), and increased 
Table 1. Characteristics of TBI patients according to chronic QOL state.

\begin{tabular}{|c|c|c|c|c|}
\hline \multirow{2}{*}{ Variables } & \multirow{2}{*}{$\begin{array}{l}\text { All patients } \\
(\mathrm{n}=226)\end{array}$} & \multicolumn{2}{|c|}{ QOL } & \multirow{2}{*}{ P-value } \\
\hline & & Favorable $(\mathrm{n}=118)$ & Unfavorable $(\mathrm{n}=108)$ & \\
\hline Gender\% & & & & $\mathrm{NS}^{*}$ \\
\hline Male & 78.8 & 93.9 & 93.5 & \\
\hline Female & 21.2 & 6.1 & 6.5 & \\
\hline \multicolumn{5}{|l|}{ Age range\% } \\
\hline Young (18 - 40 years) & 66.8 & 43.3 & 56.5 & 0.029 \\
\hline Aging (41 - 65 Years) & 33.2 & 57.1 & 44.5 & \\
\hline \multicolumn{5}{|l|}{ Education level\% } \\
\hline Basic & 41.2 & 41.1 & 50 & NS \\
\hline Moderate & 50.2 & 52 & 47.2 & \\
\hline Academic & 8.6 & 6.8 & 2.8 & \\
\hline \multicolumn{5}{|l|}{ Lesion Type\% } \\
\hline Hemorrhages & 50.2 & 48.6 & 50.8 & 0.002 \\
\hline Contusion & 13.2 & 17.6 & 6.5 & \\
\hline Pneumocephalus & 7.4 & 11.5 & 3.9 & \\
\hline Accompanied hemorrhage & 11.7 & 6.1 & 13.4 & \\
\hline Skull fracture & 10.5 & 11 & 15.2 & \\
\hline Diffuse axonal injury & 7 & 5.2 & 10.2 & \\
\hline \multicolumn{5}{|l|}{ Lesion Site\% } \\
\hline Frontal & 25.2 & 26.4 & 20.2 & 0.004 \\
\hline Temporal & 13.2 & 11.5 & 10.4 & \\
\hline Parietal & 11.5 & 20.9 & 3.7 & \\
\hline Occipital & 3.8 & 4.7 & 2.8 & \\
\hline Multifocal & 40.1 & 32.4 & 50.1 & \\
\hline brainstem & 6.2 & 4 & 12.8 & \\
\hline Brain injury severity\% & & & & $0 / 001$ \\
\hline Severe & 12.1 & 5.4 & 21.3 & \\
\hline Moderate & 33.5 & 25 & 45.4 & \\
\hline Mild & 54.5 & 69.6 & 33.3 & \\
\hline Neurosurgical intervention\% & 40.1 & 41.9 & 38 & NS \\
\hline ISS Score(M \pm SD) & $12.28 \pm 21.48$ & $8.83 \pm 17.28$ & $13.95 \pm 27.28$ & 0.001 \\
\hline $\begin{array}{l}\text { Time course post initial injury till discharge } \\
\text { (day } \mathrm{M} \pm \mathrm{SD} \text { ) }\end{array}$ & $4.3 \pm 9.23$ & $3.2 \pm 59.7$ & $4.7 \pm 11.61$ & 0.002 \\
\hline Duration of ICU (day M \pm SD) & $1.64 \pm 3.04$ & $1.32 \pm 0.3$ & $0.86 \pm 2.31$ & 0.001 \\
\hline
\end{tabular}

\footnotetext{
${ }^{*}$ Not significant.
}

length of ICU stay (mean \pm SD: $2.31 \pm 0.86$, $\mathrm{t}=3.66$, $\mathrm{df}=224, \mathrm{P}>0.001$ ) were more likely at risk of the chronic unfavorable QOL. The more the time course after initial injury till discharge, the more the probability of chromic unfavorable QOL would be (mean \pm SD: $11.61 \pm 4.7, \mathrm{t}=5.12$, $\mathrm{df}=224, \mathrm{P}>0.002$ ). Severity of brain injury $(\mathrm{P}<0.001)$, type of lesion $(\mathrm{P}<0.004)$ and site of lesion $(\mathrm{P}<0.003)$ were risk factors of unfavorable $\mathrm{QOL}$. Multifocal lesions (50.1\%) and hemorrhages (50.8\%) were successively more common lesion types and sites in 
patients who reported unfavorable QOL 6 months after TBI. Patients with poor chronic QOL had severe (21.3\%) and moderate (45.4\%) brain damage. More details are presented in Table 1. Result of the neuropsychological evaluations at discharge is shown in Table 2. In victims having post-traumatic psychiatric disorder $(\mathrm{P}>0.03)$, pragmatic linguistic disorder $(\mathrm{P}>0.01)$ and Agnosia $(\mathrm{P}>0.005)$, chronic unfavorable QOL was significantly more possible. Disability in performing neuropsychological tasks which increased the risk of chronic unfavorable QOL include, logical memory (mean \pm SD: $8.22 \pm 3.11$, $\mathrm{t}=2.39$, $\mathrm{df}=224, \mathrm{P}>0.02$ ), verbal paired associate (mean \pm SD: $7.5 \pm 2.91, \mathrm{t}=3.09, \mathrm{df}=224, \mathrm{P}>0.005$ ), word discrimination (mean \pm SD: $10.90 \pm 4, \mathrm{t}=5.1 \mathrm{df}=$ 224, $\mathrm{P}>0.003$ ), simple commands (mean \pm SD: $3.92 \pm 1.79$, $\mathrm{t}=4.06$, $\mathrm{df}=224, \mathrm{P}>0.002$ ), and semantic acceptability (mean \pm SD: $5.69 \pm 4.26$, $t=2.68$, df $=224, \mathrm{P}>0.02$ ). According to Table 3 final step of logistic regression analysis to determine the predictors of physical and mental QOL in patients with chronic TBI indicated that TBI severity $(\mathrm{OR}=-0.216 ; 95 \% \mathrm{CI}=-0.087-0.975)$, logical memory score $(\mathrm{OR}=-0.925 ; 95 \% \mathrm{CI}=0.877$ $-0.975)$, semantic acceptability score (OR $=-0.928$; $95 \% \mathrm{CI}=0.894-0.962)$, and simple commands score (OR $=-1.045 ; 95 \% \mathrm{CI}=1.028-1.063)$ were the strong significant predictors for chronic mental QOL, respectively. TBI severity $(\mathrm{OR}=-0.406 ; 95 \% \mathrm{CI}=0.288-0.917)$, ISS score $(\mathrm{OR}=-0.893 ; 95 \% \mathrm{CI}=0.844-0.945)$ and multifocal lesions $(\mathrm{OR}=1.012$; 95\% CI $=1.009$ - 1.031) were the most significant predictors of chronic physical QOL, successively.

\section{Discussion}

Following TBI, a series of neurochemical events occurs, leading to secondary long-term and molecular and neuronal alters along with behavioral, emotional and cognitive changes. These events are more serious in severe damages. In this essay, both severe and moderate brain damages were related to poor QOL. The prediction ability of TBI severity for QOL in chronic phase in several studies became apparent [20]-[22]. All patients were discharged with good recovery or mild disability; however, patients with poor verbal memory, logical memory, semantic acceptability and auditory comprehension functions demonstrated chronic unfavorable QOL. Linguistic skill which necessitates complex cognitive demands as semantic acceptability depends on executive function process of bilateral prefrontal lobe which is very vulnerable in TBI patients and its deficit is observed in patients with severe communicative deficit [23]. Such higher mental function play a crucial role in a process which we refer as intelligence or abstract thinking and its impairment leads to decreased thinking independence and weak decision-making, making life dependent on environmental support to varying degrees. The results were consistent with those of McCarthy (2006) and Philip \& Henry (2005) [10] [24]. Studies suggest that following trauma, poor problem-solving in daily activities can cause inefficient relationship and make the psychosocial dimensions

Table 2. Univariate analysis of neuropsychological tasks and other elements according to chronic QOL state.

\begin{tabular}{|c|c|c|c|}
\hline \multirow{2}{*}{ Neuropsychological Scores and post-traumatic disorders } & \multicolumn{2}{|c|}{ Quality of life } & \multirow{2}{*}{ P-value } \\
\hline & Unfavorable & Favorable & \\
\hline Post-traumatic agnosia\% & 46.3 & 16.32 & 0.005 \\
\hline Post-traumatic apraxia\% & 11.42 & 9.55 & $\mathrm{NS}^{*}$ \\
\hline Post-traumatic disarthria\% & 34.13 & 32.17 & NS \\
\hline Post-traumatic pragmatic linguistic disorder\% & 30.6 & 18.9 & 0.01 \\
\hline Post-traumatic psychiatric disorder\% & 44.29 & 21.98 & 0.03 \\
\hline Logical memory $\mathrm{M} \pm \mathrm{SD}$ & $8.22 \pm 3.11$ & $13.47 \pm 4.56$ & 0.02 \\
\hline Visual memory $\mathrm{M} \pm \mathrm{SD}$ & $9.83 \pm 2.89$ & $10.07 \pm 2.3$ & NS \\
\hline Verbal paired associates $\mathrm{M} \pm \mathrm{SD}$ & $7.5 \pm 2.91$ & $11.64 \pm 3.5$ & 0.005 \\
\hline Word discrimination $\mathrm{M} \pm \mathrm{SD}$ & $10.90 \pm 4$ & $16.87 \pm 5.53$ & 0.003 \\
\hline Simple commands $\mathrm{M} \pm \mathrm{SD}$ & $3.92 \pm 1.79$ & $4.56 \pm 1.05$ & 0.002 \\
\hline Confronting naming $\mathrm{M} \pm \mathrm{SD}$ & $8.10 \pm 4.63$ & $8.35 \pm 4.79$ & NS \\
\hline Semantic acceptability $\mathrm{M} \pm \mathrm{SD}$ & $5.69 \pm 4.26$ & $7.92 \pm 3.78$ & 0.02 \\
\hline Semantic categories $\mathrm{M} \pm \mathrm{SD}$ & $2.54 \pm 2.24$ & $3.02 \pm 2.33$ & NS \\
\hline
\end{tabular}

\footnotetext{
"Not significant.
} 
Table 3. Final step of multiple logistic regression model to predict chronic physical and mental QOL.

\begin{tabular}{cccccc}
\hline QOL aspects & Predictors & $\mathrm{B}^{*}$ & OR $^{* * *}$ & P-value & CI95\% $^{* * * *}$ \\
\hline \multirow{3}{*}{ Mental QOL } & TBI severity & -1.534 & 0.216 & 0.004 & $0.534-0.087$ \\
& Logical memory score & -0.078 & 0.925 & 0.002 & $0.975-0.877$ \\
& Semantic acceptability score & -0.075 & 0.928 & 0.001 & $0.964-0.894$ \\
& Simple commands score & 0.044 & 1.045 & 0.01 & $1.063-1.028$ \\
Physical QOL & TBI severity & -1.092 & 0.406 & 0.001 & $0.288-0.917$ \\
& ISS score & -0.113 & 0.893 & 0.027 & $0.945-0.844$ \\
\hline
\end{tabular}

${ }^{*} \beta$ coefficient; ${ }^{* *}$ Odd Ratio; ${ }^{* * *}$ Confidence Interval $95 \%$.

of life problematic in chronic phase [10] [14] [25] [26]. The result of multivariate analyses highlighted logical memory function at discharge as a predictive factor of chronic mental QOL. In previous efforts, it was found that more severe brain injuries and loss of consciousness (LOC) diminishes the memory quotient of TBI victims compared to those without neurological complications with same age [27]. The relationship between chronic auditory memory and auditory comprehension was clarified in Leaf's study [28]. Auditory comprehension is one of the essential items in social communication [24], and its deficit is a prominent sign of Wernicke and sensory transcortical aphasia which is observed more in patients with severe brain lesions [29]. In existing research, low score of auditory comprehension skill had an adverse effect on mental QOL. Furthermore, post discharge problematic relationship leads to problematic behaviors and psychiatric symptoms such as depression, agitation and aggression in some patients which have very adverse effect on QOL [30]. Mah et al. stated that deficits in comprehension of social concepts and agreements mostly occur due to orbitofrontal lobe damage which decreases the ability to evaluate the facial emotional expressions [31]. In our study, defective post-traumatic pragmatic linguistic skill was one of effective factors on QOL which has a close relationship with social and communicative skills according to mentioned researchers. The lower the score according to ISS, the less the severity of traumatic organs injury would be. Diminished physical independence of patients makes their individual role less eminent in daily and social activities and more dependent on environment and people around. Therefore, this, in turn, marks a physical poor QOL. In ongoing study, it was found that lesion site in neuroimaging findings could predict chronic physical QOL. This finding was not consistent with results of Almeida Lima's work and his colleagues who believed that initial CT results could not predict chronic QOL [9]. The cause of this discordance can be due to different methodologies.

\section{Conclusion}

Overall, earlier adverse neuropsychological outcomes most prominently logical memory loss, deficient auditory comprehension and disturbed mental processes related to high levels of language result in reduced mental QOL during first 6 months after injury and decrease of the social participation of patients. Thus, early rehabilitation schedule should be considered to prevent progressive adverse verbal and auditory outcomes. One limitation of our study was $12 \%$ dropout of subjects in follow-up phase 6 months after injury. We also did not consider recurrent lesion and rehabilitation therapy for patients after discharge which confounded the results of QOL. Based on the results, it is suggested that researches be designed in which the effect of rehabilitation intervention on improving the variant domains of QOL emphasizing verbal fields in patients with moderate and severe TBI should be examined.

\section{Acknowledgements}

We offer our special thanks to Guilan Road Trauma Research Centre and Clinical Research Development Unit of Poursina Hospital for supporting us, and Ms. Fatemeh Javadi for editing the manuscript.

\section{References}

[1] Chabok, S.Y., Safaei, M., Hemati, H., Mohammadi, H., Ahmadi, D.M., Shabani, S. and Kouchakinezhad, L. (2000) 
Epidemiology of Head Injury in Patients Who Were Referred to Poorsina Hospital. Journal of Guilan University of Medical Sciences, 16, 112-119.

[2] Henry, J.D. and Crawford, J.R. (2004) A Meta-Analytic Review of Verbal Fluency Performance in Patients with Traumatic Brain Injury. Neuropsychology, 18, 621-628. http://dx.doi.org/10.1037/0894-4105.18.4.621

[3] Aitken, L.M., Davey, T.M., Ambrose, J., Connelly, L.B., Swanson, C. and Bellamy, N. (2007) Health Outcomes of Adults 3 Months after Injury. Injury, 38, 19-26. http://dx.doi.org/10.1016/j.injury.2006.05.020

[4] Angeleri, R., Bosco, F.M., Zettin, M., Sacco, K., Colle, L. and Bara, B.G. (2008) Communicative Impairment in Traumatic Brain Injury: A Complete Pragmatic Assessment. Brain \& Language, 107, 229-245. http://dx.doi.org/10.1016/j.bandl.2008.01.002

[5] Chapey, R. (2008) Language Intervention Strategies in Aphasia and Related Neurogenic Communication Disorders. Chapter 33, 5th Edition, Lippincott Williams \& Wilkins, Philadelphia.

[6] Smith, D.H. (2006) Mild Traumatic Brain Injury and Psychiatric Illness. BCMJ, 48, 510-514.

[7] Pagulayan, K.F., Temkin, N.R., Machamer, J. and Dikmen, S.S. (2006) A Longitudinal Study of Health-Related Quality of Life after Traumatic Brain Injury. Archives of Physical Medicine and Rehabilitation, 87, 611-618. http://dx.doi.org/10.1016/j.apmr.2006.01.018

[8] Johnston, M.V., Goverover, Y. and Dijkers, M. (2005) Community Activities and Individuals Satisfaction with Them: Quality of Life in the First Year after Traumatic Brain Injury. Archives of Physical Medicine and Rehabilitation, 86, 735-745. http://dx.doi.org/10.1016/j.apmr.2004.10.031

[9] De Almeida Lima, D.P., Filho, C.S., De Campos Vieira Abib, S. and De Figueiredo, P.D. (2008) Quality of Life and Neuropsychological Changes in Mild Head Trauma Late Analysis and Correlation with S100B Protein and Cranial CT Scan Performed at Hospital Admission. Injury, 39, 604-611. http://dx.doi.org/10.1016/j.injury.2007.11.008

[10] McCarthy, M.L., Dikmen, S.S., Langlois, J.A. and Selassie, A.W. (2006) Self-Reported Psychosocial Health among Adults with Traumatic Brain Injury. Archives of Physical Medicine and Rehabilitation, 87, 953-961. http://dx.doi.org/10.1016/j.apmr.2006.03.007

[11] Scharbrodt, W., Stein, M., Schreiber, V., Boker, D.K. and Oertel, M.F. (2009) The Prediction of Long-Term Outcome after Subarachnoid Hemorrhage as Measured by the Short Form-36 Health Survey. Journal of Clinical Neuroscience, 16, 1409-1413. http://dx.doi.org/10.1016/j.jocn.2009.01.011

[12] Upadhyay, D. (2007) Quality of Life in Traumatic Brain Injured Patients. World Applied Sciences Journal, 2, 687-690.

[13] Rengachary, S.S. and Ellenbogen, R.G. (2005) Principle of Neurosurgery. Chapter 19, 2nd Edition, Elsevier Mosby, Maryland Heights.

[14] Baker, S.P., O’Neill, B., Haddon Jr., W. and Lonq, W.B. (1974) The Injury Severity Score: A Method for Describing Patients with Multiple Injuries and Evaluating Emergency Care. Journal of Trauma-Injury Infection \& Critical Care, 14, 187-196. http://dx.doi.org/10.1097/00005373-197403000-00001

[15] Nilipour, R. (1993) Persian Aphasia Test. Iran University of Medical Science, Tehran.

[16] Paradis, M. (1989). Bilingual Aphasia Test. Lawrence Erlbaum Associates Inc., New Jersey.

[17] Marnat, G.G. (2003) Handbook of Psychological Assessment. Chapter 6, 4th Edition, Wiley, Hoboken.

[18] Noorbala, A.A., Mohammad, K. and Bagheri-Yazdi, S.A. (1998) The Epidemiological Study of Psychiatric Disorders in Tehran. Hakim Journal, 4, 212-223.

[19] Montazeri, A., Goshtasebi, A., Vahdaninia, M. and Gandek, B. (2005) The Short Form Health Survey (SF-36): Translation and Validation Study of the Iranian Version. Quality of Life Research, 14, 875-882. http://dx.doi.org/10.1007/s11136-004-1014-5

[20] Deb, S., Lyons, I., Koutzoukis, C., Ali, I. and McCarthy, G. (1999) Rate of Psychiatric Illness 1 Year after Traumatic Brain Injury. The American Journal of Psychiatry, 156, 374-378.

[21] Anderson, V., Brown, S., Newitt, H and Hoile, H. (2009) Educational, Vocational, Psychosocial, and Quality of Life Outcome for Adult Survivors of Childhood Traumatic Brain Injury. Journal of Head Trauma Rehabilitation, 24, 303312. http://dx.doi.org/10.1097/HTR.0b013e3181ada830

[22] Hutter, B.O., Kreitschmann-Andermahr, I. and Gilsbach, J.M. (2001) Health-Related Quality of Life after Aneurysmal Subarachnoid Hemorrhage: Impacts of Bleeding Severity, Computerized Tomography Findings, Surgery, and Neurological Grade. Journal of Neurosurgery, 94, 241-251. http://dx.doi.org/10.3171/jns.2001.94.2.0241

[23] Chua, S.E., Cheung, C., McAlonan, G.M., Lam, I.W.S., Cheung, V., Wong, T.K.W, et al. (2005) Functional Magnetic Resonance Imaging Evaluation of Bilateral Brain Activation in Chinese Speech. Hong Kong Journal of Psychiatry, 15, 77-81.

[24] Henry, J.D., Phillips, L.H., Crawford, J.R., Theodorou, G. and Summers, F. (2006) Cognitive and Psychosocial Corre- 
lates of Alexithymia Following Traumatic Brain Injury. Neuropsychlogia, 44, 62-72. http://dx.doi.org/10.1016/j.neuropsychologia.2005.04.011

[25] Baldo, J.V., Bunge, S.A., Wilson, S.M. and Dronkers, N.F. (2010) Is Relational Reasoning Dependent on Language? A Voxel-Based Lesion Symptom Mapping Study. Brain and Language, 113, 59-64.

http://dx.doi.org/10.1016/j.bandl.2010.01.004

[26] Baldo, J.V., Dronkers, N.F., Wilkins, D., Ludy, C., Paskin, P. and Kim, J. (2005) Is Problem Solving Dependent on Language? Brain and Language, 92, 240-250. http://dx.doi.org/10.1016/j.bandl.2004.06.103

[27] Langeluddecke, P.M. and Lucas, S.K. (2003) Wechsler Adult Intelligence Scale-Third Edition: Findings in Relation to Severity of Brain Injury in Litigants. The Clinical Neuropsychologist, 17, 273-284. http://dx.doi.org/10.1076/clin.17.2.273.16499

[28] Leaf, A.P., Schofield, T.M., Crinion, J.T., Seghier, M.L., Grogan, A., Green, D.W. and Price, C.J. (2009) The Left Superior Temporal Gyrus Is a Shared Substrate for Auditory Short-Term Memory and Speech Comprehension: Evidence from 210 Patients with Stroke. Brain, 132, 3401-3410. http://dx.doi.org/10.1093/brain/awp273

[29] Chabok, S.Y., Kapourchali, S.R., Leili, E.K., Saberi, A. and Mohtasham-Amiri, Z. (2012) Effective Factors on Linguistic Disorder during Acute Phase Following Traumatic Brain Injury in Adults. Neuropsychologia, 50, 1444-1450. http://dx.doi.org/10.1016/j.neuropsychologia.2012.02.029

[30] Savundranayagam, M.Y., Hummert, M.L. and Montgomery, R.J. (2005) Investigating the Effects of Communication Problems on Caregivers Burden. The Journals of Gerontology: Series B, 60, S48-S55. http://dx.doi.org/10.1093/geronb/60.1.S48

[31] Mah, L., Arnold, M.C. and Grafman, A. (2004) Impairment of Social Perception Associated with Lesions of the Prefrontal Cortex. The American Journal of Psychiatry, 161, 1247-1255. http://dx.doi.org/10.1176/appi.ajp.161.7.1247 